\title{
Death photography in Turkey in the late 1800s and early 1900s: Defining an area of study
}

\section{Pelin Aytemiz}

To cite this article: Pelin Aytemiz (2013) Death photography in Turkey in the late 1800s and early 1900s: Defining an area of study, Early Popular Visual Culture, 11:4, 322-341, DOI: 10.1080/17460654.2013.831738

To link to this article: http://dx.doi.org/10.1080/17460654.2013.831738

曲 Published online: 19 Nov 2013.

Submit your article to this journal $匚$

III Article views: 351

Q View related articles $\sqsubset$

4 Citing articles: 1 View citing articles 


\title{
Death photography in Turkey in the late 1800s and early 1900s: Defining an area of study
}

\author{
Pelin Aytemiz* \\ Department of Art, Design and Architecture, Ihsan Doğramacı Bilkent University, Ankara, \\ Turkey
}

\begin{abstract}
Since its invention, photography has been associated with the personal past. Although photographs seem to bring back memories and the past, by visually representing the inevitable passing of time, they also serve as melancholic objects of loss that remind us of our mortality. The critical literature has frequently associated photography with death. Yet when the image includes a dead body, the focus of discussion alters. Post-mortem photography was a popular visual tradition in nineteenth-century North America and Western Europe, photographs of the deceased being taken as expressions of grief. However, in the history of photography in Turkey, a Muslim-majority country, post-mortem photographs are rarely mentioned. This article delves into photography archives and collections in Turkey, which constitute an unmapped and obscure territory. It attempts to discover and discuss various death-related photographs in Turkey that can be compared to the Victorian post-mortem photography tradition. The article also aims to expand the parameters of the discussion on the relationship between different types of photography and mourning, remembering, longing for, and bidding farewell to the dead. Different ways of expressing grief via photography after the death of a loved one and the way death is constructed in front of the camera to express mourning and longing are among the main topics of discussion.
\end{abstract}

Keywords: death; dead body; mourning; early photography in Turkey; postmortem photography

Every photograph is a regret; it is an end.

Luc Sante ${ }^{1}$

Beginning in the 1840 s, with the invention of daguerreotype technology, taking a picture of a deceased loved one, as a form of a family farewell, became a popular visual practice of mourning and memorialization, especially in the Victorian era in North America and Western Europe (Burns 1990; Ruby 1995; Batchen 2004 and Linkman 2011). Photography superseded older ways of securing the memory of the deceased, such as posthumous paintings and death masks. Yet post-mortem photographs are discursively absent from the history of photography in Muslim-majority Turkey. They are also not mentioned in the historical periodical press in Turkey. The absence of post-mortem photography as a popular visual practice in Turkey might

*Email: pelinaytemiz@gmail.com 
be partially due to religious restrictions on images in a Muslim context. Despite the differences between various regions, periods and theological explanations, in Islam there has been a restrained attitude towards representational arts such as drawing and portraits, as well as idols and sculptures. Annemarie Schimmel argues that this attitude is 'basically in tune with the stark monotheistic doctrine that there is no creator but God: to produce a likeness of anything might be interpreted as an illicit arrogation of the divine creative power by humans' (cited in Larsson 2011, 53). In addition to the popular Muslim aversion to image making, perhaps perceived as an imitation of God's act of creation, in Turkey photographic technology met resistance because it was first introduced by non-Muslim minority groups living in Istanbul, and thus those who kept images were accused of imitating the 'unbelievers' (Göran Larsson 2011, 56). Nevertheless photography, namely portrait photography, gradually became popular among the Ottoman royal dynasty and reached a climax of popularity during Sultan Abdülaziz's reign (1861-76) (Öztuncay 2005, 260). Nonetheless, taking photographs of dead loved ones remained a marginal act among the Muslim population.

Bahattin Öztuncay is one of the rare researchers to discuss mourning photography in relation to Turkish culture. He regards post-mortem photographs produced in Istanbul during the Ottoman Empire as exceptional because it was rare, even for the living, to be photographed in the Muslim society of the period $(2003,67)$. Edhem Eldem further explains why post-mortem photography was not popular in the Turkish Muslim community:

Although the rule forbidding portrayal was violated, the Islamic traditions of burial were strictly followed, in which the body of the deceased without being exhibited is immediately washed, enshrouded and buried. Therefore, there is nothing surprising about not finding a single example of post-mortem photography in a Muslim society. (2005, 256; author's translation).

This article shows that although there was religious aversion to representational arts and a taboo about the visual depiction of the deceased, photographs of the dead were indeed taken in Turkey. It deals with the question of how photography was

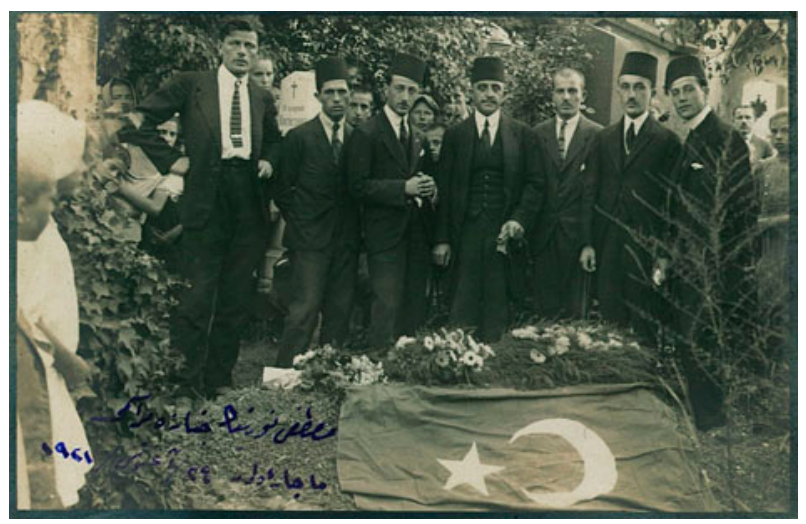

Figure 1. A group assembled at a graveside in İstanbul. The Ottoman Turkish note on the photograph reads: 'Mustafa Nuri, 24.8.1921' Author's private collection. 
used as a tool for grieving and explores the different ways in which loss was (re) constructed in mourning photography in Turkey in the late 1800s and early 1900s, the period when the practice of taking post-mortem photographs began and became popular in the West. Moreover, this article suggests that despite the absence of post-mortem photography in its classical Victorian sense, alternative practices of photographically depicting and mourning the absence of the beloved dead were popular in Turkey in the late 1800s and early 1900s. These photographs are not simply photographs that depict corpses; they can instead be described as dispossessed mourning photographs that construct loss by visually narrating the mourner's grief. Focusing on this incidental sample of dispossessed photographs, this article attempts to define them in more detail than has previously been achieved and to refine a new area of study concerning death photography in Turkey and, potentially, among Muslim cultures.

The research for this article began in 2009 with the purpose of investigating the presence or absence of the post-mortem photography tradition within the domain of the family in Turkey through archival research. Yet various dead ends (discussed below) encountered in locating and uncovering materials led to new conceptual paths, to several U-turns in the logic in assessing the material, and to an alternative categorization and conceptualization of the available photographs. Although the author visited many formal photography archives, the primary source materials also include photographs obtained from private collectors, antique markets, flea markets, secondhand bookstores and online auction sites in Turkey.

\section{The dead ends and the dead in the archives}

In Turkey, there are few archives or libraries that hold photographic collections; moreover, when collections exist they are not always accessible. ${ }^{2}$ Historian Oktay Özel $(2012,27)$ attributes the temporary closing of archive collections to the whims of the political will, shaped according to circumstances at the time. Some collections, even though theoretically available to researchers, are in practice inaccessible because of the institution's inadequate cataloguing systems (Özel 2012, 27). In others, though the archives are well organized, catalogued and digitized, staff do not allow researchers direct access to either the original photographs or to the digital copies. Browsing through titles that are vague and not sufficiently descriptive also prevents a thorough search of the archives. This situation was a serious problem in terms of researching a genre of images that is not acknowledged and does not exist in the terminology of Turkish society in general. There is no definite Turkish word that defines the particular ritual of photographing 'the beloved deceased'. The (translated) term 'photographs of the dead' is not a suitable way of defining for the searched-for item (a memorial post-mortem photograph), as it does not correspond to the particular practice of interest, recalling contexts outside the scope of the research. This difficulty in naming and defining this particular photographic genre is most probably due to the fact that it is not commonly applied in the Turkish context. This lack of a concept points not only to the absence of the practice of postmortem photography, but also to its discursive absence. In this respect, this article's attempt to define and refine an unmapped and obscure territory by bringing to light novel materials, which have not been previously acknowledged within the framework of post-mortem photography, is significant for the history of photography (Figure 2). 


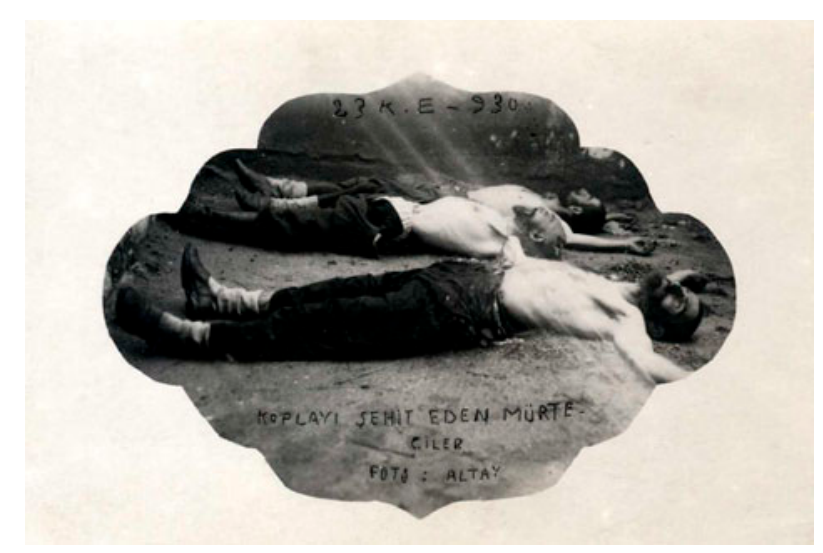

Figure 2. The corpses of the murderers of Kubilay, by Foto Altay, 1930, İstanbul. Courtesy of the archives of the Turkish Revolution History Institute.

In addition to the encountered problems of taxonomy, the formal archives mostly contain photographs of historical and political value; they usually do not have photographs of domestic life, portraits, or family photographs. Given the private nature of post-mortem imagery, then, these types of photographs are even more difficult to find in poorly catalogued formal archives.

Many photographs of the dead that were located in the archives did not properly relate to mourning photography, which post-mortem photography is a part of. Öztuncay argues that photographs of the dead taken after or during war, armed conflicts or criminal acts and that are to be used as news items are not to be included within the definition of post-mortem photography (2003, 67). Such photographs, probably taken for their news value, can be classified as photographs of violent death and should be distinguished from mourning photographs, where the cause of death was usually unremarkable. Although this article is concerned with personal mourning photographs taken as a part of families' daily life practices, an exploration of these violent death photographs and how they differ from mourning photographs can clarify this article's main object of study. The corresponding photographs can be divided into four contextual categories: (1) natural disasters; (2) forensics and medical education; (3) war/capital punishment; and (4) those at the thresholds of public-private domains and histories.

\section{Natural disasters}

Images of the dead taken following natural disasters usually portray newsworthy events rather than expressions of personal mourning. They are immortalized not as personal remembrances but as historical documents, which were probably not produced as a response to requests from family members. The bodies in such images (Figure 3) function as if they are part of the destruction itself. They can be categorized under journalistic snapshots as they lack any deliberate construction or iconography. 


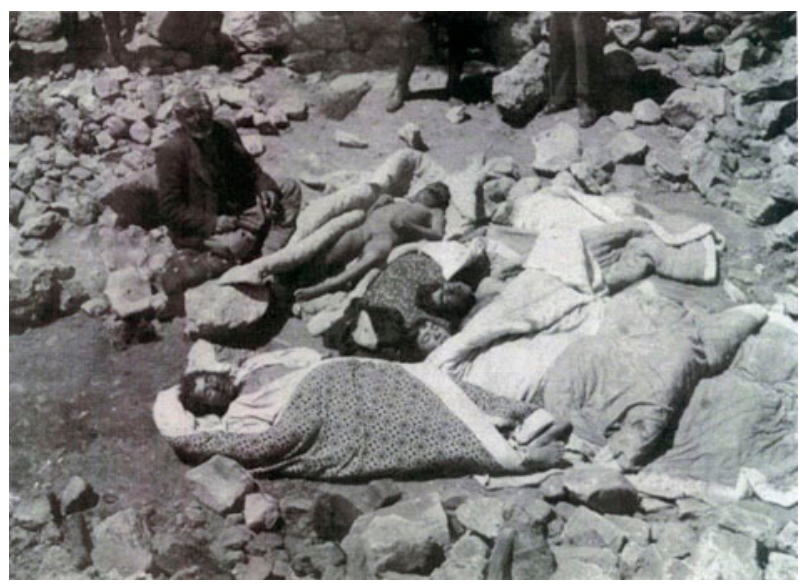

Figure 3. After an earthquake, Turkey. Courtesy of the archives of Turkish Red Crescent.

\section{Forensics and medical education}

In photographs produced for medical education (Figure 4), death is not hidden, secret or something to be avoided, as it is in some Victorian post-mortem photographs. ${ }^{3}$ Death is made clearly visible through explicitly presenting the dead body for the professional gaze. Bodies that have been skinned appear as if their subjectivities have also been stripped off. In medical photography, bodies are usually not identified and are objects of scientific research; the totality of the body, fragmentation, alienation, and estrangement are the foci. The dead body is seen as an object/ structure to be explored by students and professors. For medical professionals, as Hallam, Hockey and Howard state, 'the corpse is an objective source of knowledge; while for bereaved people it is not simply a body but a person' $(1999,15)$. Unlike post-mortem photographs, in which the motivation revolves around efforts to humanize the cadaver (as in the efforts of embalmers to remove signs of damage and illness in order to make the lifeless body seem familiar to family and friends), ${ }^{4}$

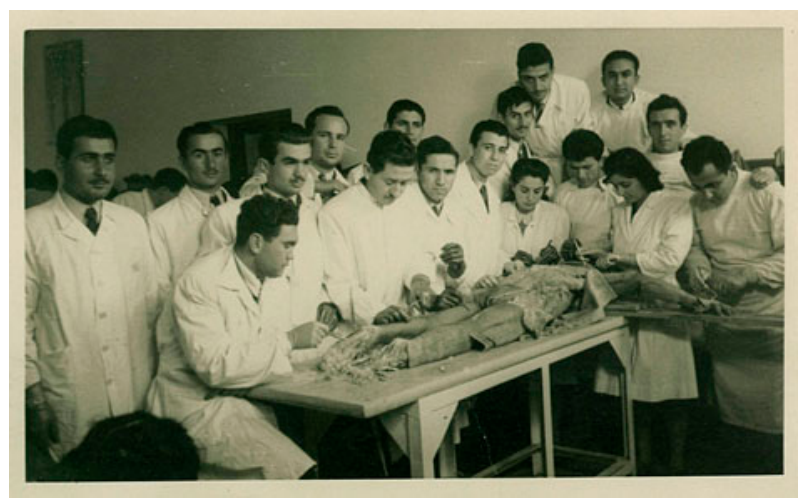

Figure 4. Body of a deceased person on the autopsy table, surrounded by medical students, 1947. Author's private collection. 
In photographs such as the one reproduced in Figure 4, the emphasis is more on the living than the dead. Being around the dead body, and the processes carried out on it, seem to be the foci of attention.

In the domain of forensics (Figure 5), a dead body is used to reveal an unnatural death and to determine whether a crime was committed. The body itself is an arena for investigation. As Hallam, Hockey and Howard explain, 'the body bears a history: a medical history read via scar tissue, lesions and damaged organs; and a social history, accessed via tattoos, body piercings, clothing and other objects found on or around the body' (1999, 15). Generally, forensic photographs that are taken to witness and document an event are seen only by a few people, such as doctors and those involved in legal action. ${ }^{5}$

\section{War and capital punishment}

Those who have died in war seem to be photographed differently from those who experience an ordinary death; photographs of the former appear to represent an 'enemy' (internal or external). Several death-related photographs encountered in the archives $^{6}$ depict public prosecutions by the Istiklal Courts. ${ }^{7}$ Those who were sentenced to death for crimes against the state were photographed without hesitation because they portrayed the negative 'other'. In contrast to Victorian mourning photographs, which attempted to conceal death, these images were taken as evidence of it. There is still an issue of remembrance, but a negative one that works as an admonition. Hangings occurred in city squares and became spectacles symbolizing the power of the state. In the cases of such photographs, there is to be no discomfort in gazing upon the dead body of the enemy or the criminal.

Close-ups as well as wide shots were taken of public executions, not only to identify the body but also to document the event (Figure 6). That death in such cases was not covered, concealed, distanced or avoided can be observed in the proximity of the crowds to the deceased (Figures 7 and 8).

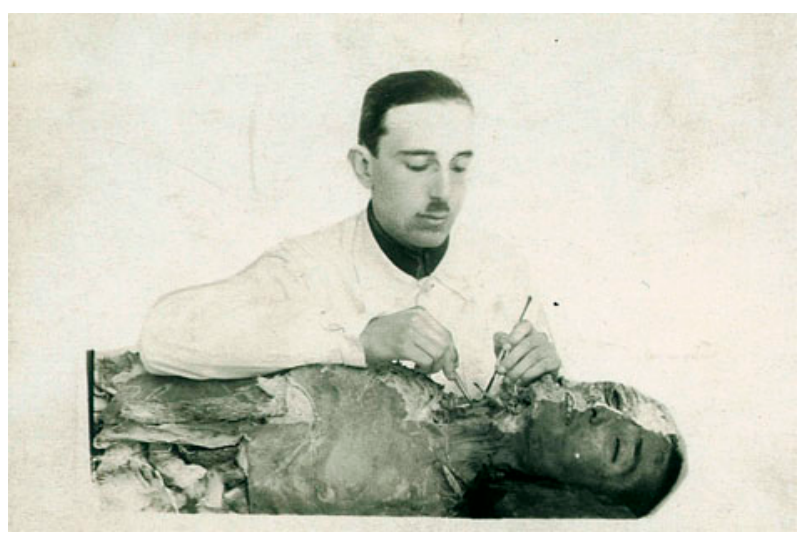

Figure 5. Dead body being examined by a specialist. The Ottoman Turkish note on the back of the photograph reads: '6.03.1913 Assessment and diagnosis, notary Hüseyin'. Author's private collection. 


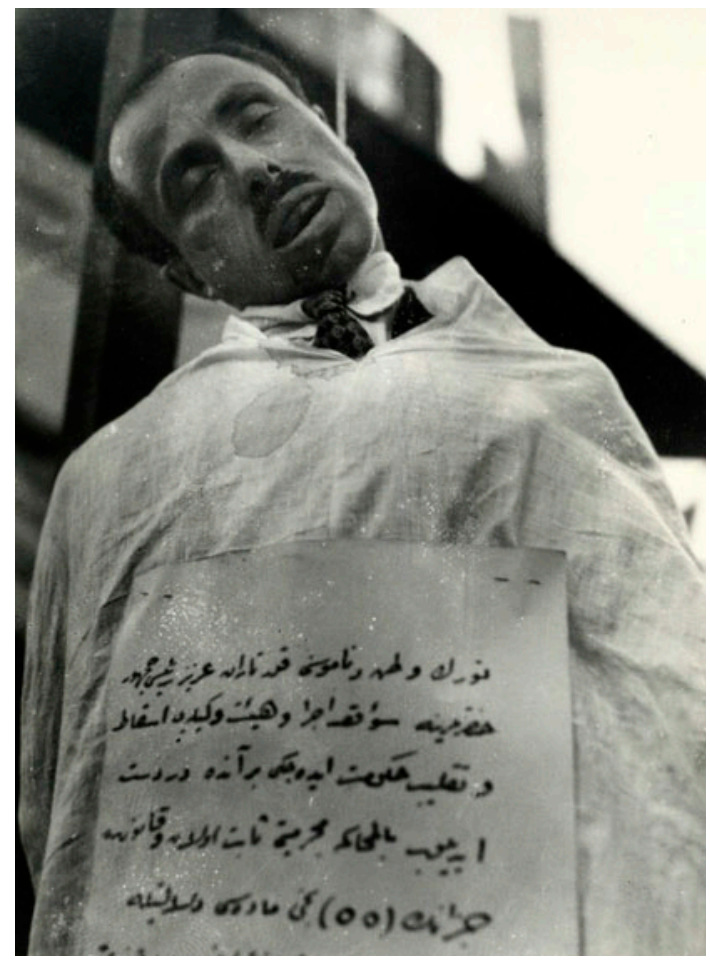

Figure 6. Photograph from executions ordered by Istiklal Court, c.1920-27. Courtesy of the archives of the Turkish Revolution History Institute.

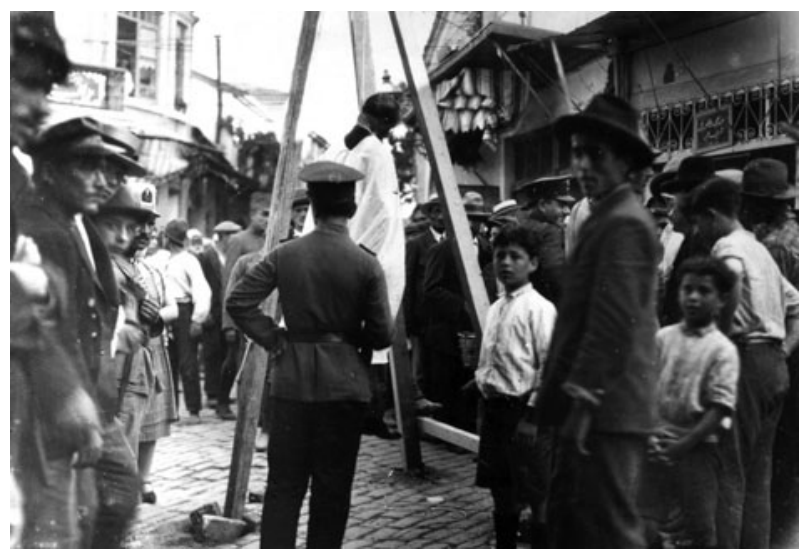

Figure 7. Photograph from executions ordered by the Izmir Istiklal Court, c.1920-27. Courtesy of the archives of the Turkish Revolution History Institute.

Until 1928 in Turkey, after a victory in war, it was normal for a handful of captured enemy soldiers to be decapitated for the purpose of publicly displaying severed heads. Sometimes the heads were sent to Istanbul as trophies and exhibited 


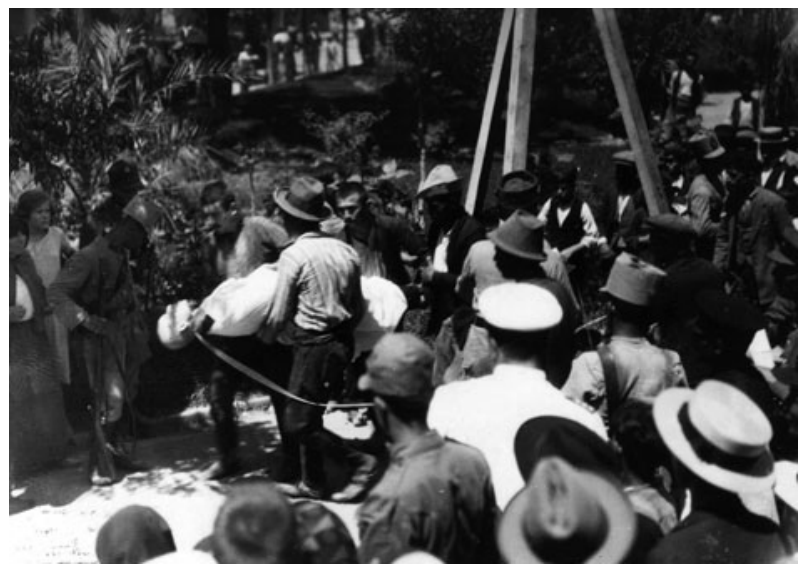

Figure 8. Photograph from executions ordered by Istiklal Court, c.1920-27. Courtesy of the archives of the Turkish Revolution History Institute.

in city squares (Eldem 2005, 188). Some studio photographs from the Ottoman era portray soldiers posing with the heads of slain enemies (Figure 9). These photographs, differing from the images of capital punishments, have a personal and performative aspect; the bodies or heads of the enemy were arranged to create a desired impression of power and triumph and functioned as a symbol of the victory of the sovereign power.

In these 'war trophy photographs' (Roberts 2012, 201), the iconography does not aim to create a feeling of mourning, and no motivation to conceal and disregard death is visible. In contrast, the death of the enemy is celebrated by including the dead body. In Figure 9, two of the bodiless heads have semi-open mouths, a common way of presenting the deceased 'other' as grotesque. Such presentations contrast the efforts to humanize the cadaver observed in Victorian post-mortem photography. Unlike the body of a loved one that is positioned as if asleep, dressed neatly, decorated with flowers and accompanied by the mourner, the dead bodies of the enemy are displayed to emphasize the pleasure and pride derived from their demise. These photographs act as evidence of the elimination of the unwanted other. The dead bodies of the other become a mise-en-scène element, a prop, a trophy that symbolized the bravery and victory of Ottoman soldiers.

All these photographic examples of violent deaths may reflect historical attitudes in Turkey towards the dead body of the 'other'. Yet they offer little insight about probable practices in the personal domain of the family and their attitudes towards the death of a loved one - that is, a photograph that might be marked with a visual narration of grief.

\section{At the thresholds of public-private domains and histories}

The photographs taken in Turkey encountered in the archives of the Red Crescent are also from a war context, yet they are extraordinary because the deceased is captured with family members in private spaces, such as at home or in the garden. ${ }^{8}$ On the back of one photograph is a handwritten note in Ottoman Turkish, which 


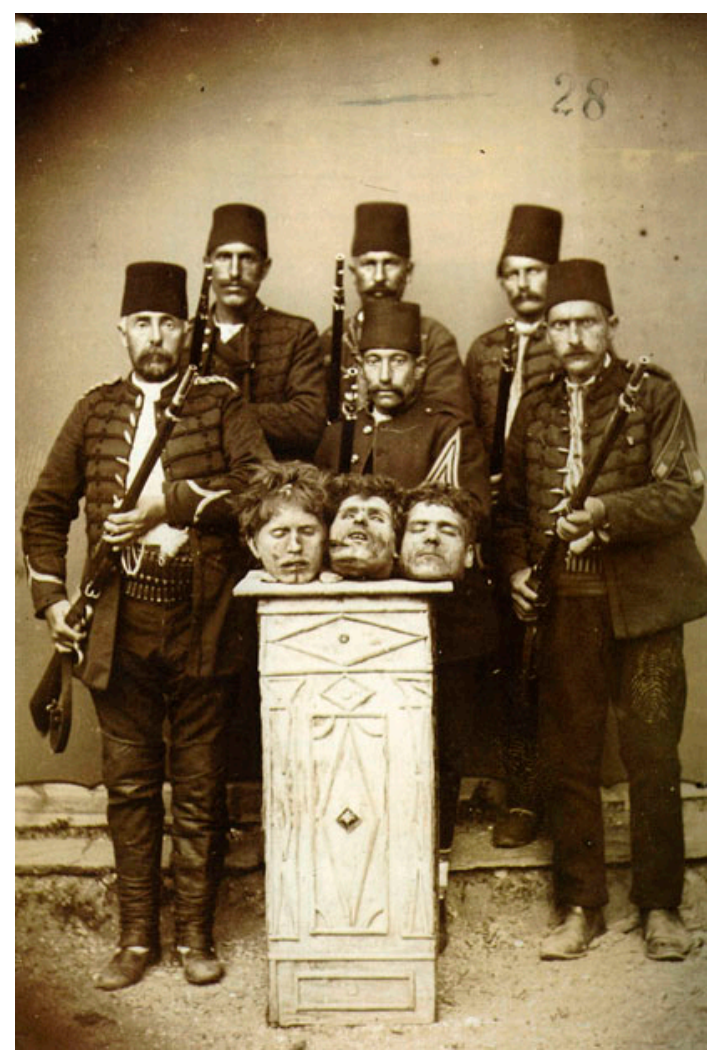

Figure 9. Ottoman-era studio photographs with heads of rebels from Macedonia or the Balkan states in the early 1900s (Eldem 2005,189 ).

reads: 'Kütahya, Ahmet Efendi. Once a mayor and member of the Municipality Council of Uşak, and a very good friend, he was tragically killed by the Greeks on 30.08.1922, who launched an assault on his house and usurped his property'. ${ }^{9}$ This inscription, documenting the details of the man's death, does not directly function as a lamentation, but still, between the lines, the mournful feelings of the writer are evident.

Coupled with the inscriptions, these photographs are not only evidence of the tragic outcomes of war, but also represent the pain of the family after the unnatural death of a loved one. These deaths are considered publicly, politically and historically crucial because they are a part of a battle. On the other hand, they are peculiar in the history of Turkish photography because they include the family in the presence of a dead body in the same photographic frame, captured in the context and space of the private acting contrary to the taboo against living people being photographed with the dead (see Figure 10).

In most of these photographs, the deceased were photographed with the family (including children), together with either a Muslim priest or a soldier (see Figures 11 and 12). A soldier who does not belong to the private domain, posing with the family, can be read as evidence of the violent death. It is as if the presence of the soldier or priest legitimizes the act of taking a last picture of the person, acting against the 


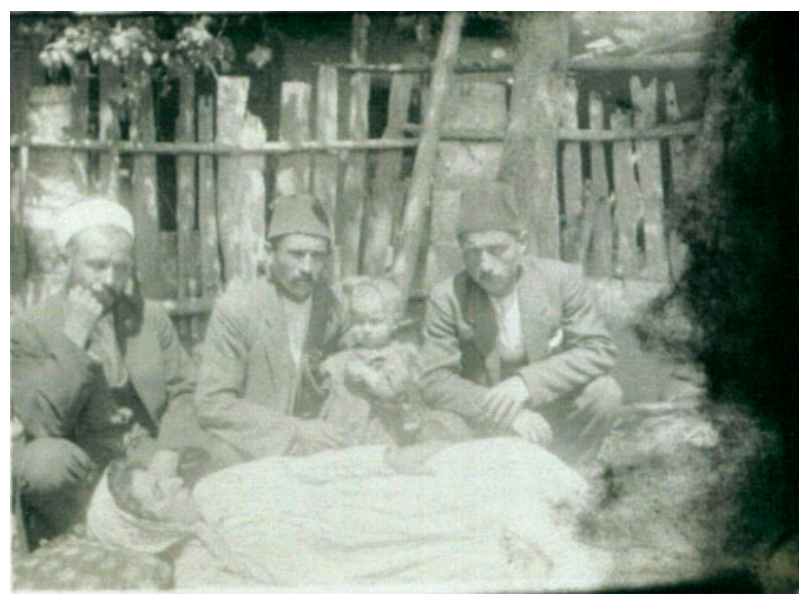

Figure 10. Family members and a Muslim priest assembled around the deceased, c.1919-23. Courtesy of the archives of the Red Crescent.

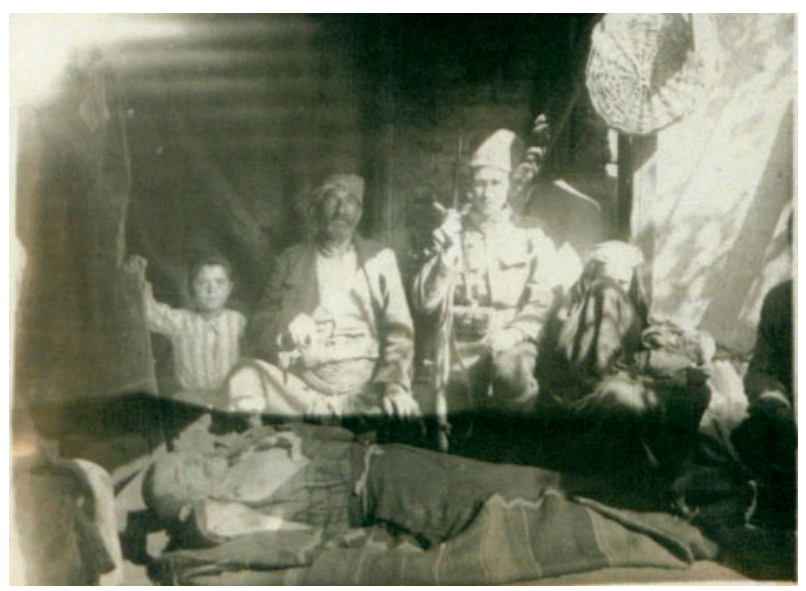

Figure 11. A post-mortem photograph including the family members of the deceased and a soldier, c.1919-23. Courtesy of the archives of the Red Crescent.

Muslim taboo of photographing the familiar dead one. Gazing at the dead body of a family member through a camera is not common practice. However, when it proves an unnatural death caused by the 'other'/enemy, the reverse seems to be true. In this sense, the photos are interesting cultural texts insofar as they cut across the usual cultural divides of public/national and private domains and histories.

The presence of children in these photographs shows that death and the dead were not hidden, particularly in a time of war. This nuance is further emphasized through the subjects directly gazing at the camera, which is an unusual way of posing in the tradition of mourning photography. To express grief and likely respect for the deceased and the inevitable fact of dying, those in post-mortem photographs are usually looking down or looking at the body (as in Figures 14 and 15). 
However, in Figures 10 and 11, by looking directly at the camera, the subjects seem to make eye contact with the viewer. Their awareness of being exposed to the camera/gaze breaks the sense of illusion and theatricality that one can observe in Victorian post-mortem photographs. There is no romantic construction of mourning in these photos, but an emphasis on the bleak reality of death. A direct gaze can be interpreted as a sign that the subjects are not afraid of the enemy or death. Bravely posing with the deceased and engaging with the viewer, the mourners align themselves with the soldier/the nation, the Muslim priest/faith and the children/the future.

Unlike post-mortem photographs taken in a studio by a professional photographer, the images discussed above bear no marks of the identity of the photographer or of the motivation for their creation. Yet it is important to contemplate the photographer's identity. ${ }^{10}$ As the images were found in a photograph album in the archives of Red Crescent, one can speculate that a member of the foundation took the photos as a means of documenting the situation. However, although the photographs resemble neither snapshots by a journalist nor studio photographs, the element of posing cannot be disregarded. Those in the photograph are looking directly at the camera, acknowledging its presence, and therefore they assume a posture in front of the beholder. The body language of the soldier in Figure 11 - how he holds his weapon and how the young boy copies his posture with a stick - is not arbitrary. These poses can be considered as an attempt to assume an identity in front of the enemy and in front of death. That the wife covers her face with her veil while holding her newborn child is also not accidental, and can be read in a number of ways: as hesitation about being photographed, as discomfort in being among strangers (the photographer, the soldier, the viewer), or as showing her respect for her dead husband.

Although the motivation is different, these families 'pose' with the deceased body of the loved one as in a Victorian post-mortem photograph. These photographs are an outcome of the merging of public and private/national concerns, and include details that could be read as expressions of bereavement and remembrance. In these photographs, one can say that the murder of a familiar person by the enemy is the focus; yet there is also a reconstruction of mourning, although it is full of pain, hatred and hope. In this sense, these images can be regarded as culturally loaded unique post-mortem photographs produced in the extraordinary conditions of war.

This brief discussion about these rare photographs in the Red Crescent archives is intended to illuminate some issues around death-related photographs in Turkish history and the visual/cultural memory. The existence of such images proves that, contrary to expectations and although not the same as Victorian post-mortem photographs, images of Muslim casualties of war were being taken in Turkey with their family members to represent mourning.

\section{Post-mortem photography in Turkey}

Faced with the difficulty, even impossibility, of carrying out the research with the material available in formal archives, the author turned to private collections, antique markets, flea markets, secondhand bookstores, and online auction websites as viable alternative sources for locating post-mortem and death-related mourning photographs. A thorough and long search through these sources indeed revealed 
many examples that might be of value, yet working with the variety of materials collected from these sources had its own methodological problems.

Sometimes the photographs lacked information such as date, context and provenance, and thus bore the problem that any discussion of them appears speculative. However, based on what is available at the moment and what is possible within the current archival conditions in Turkey, the author of this article does not see any option other than taking that risk of sounding speculative. She thus attempted to interpret the photographs through the signs they bear on their surface as soundly as possible. Therefore, in what follows, this article does not claim to be the final word on mourning photography in Turkey in a particular time period, nor does it claim that the sample of photographs used fully represents the whole genre. But, believing that formulating questions or preparing the ground to formulate new questions is as significant as providing the answers, it defines death photography in Turkey as a new area of study and develops arguments and questions that scholars may pursue or debate in the future.

The research for this article turned up many photos that looked like post-mortem imagery but in which it was difficult to determine whether the main subject was dead or alive. This dilemma resulted in an understanding that post-mortem photographs, especially those that conceal death by positioning the deceased as if in a semi-seated or sleeping position, are not entirely different from ordinary family photographs. What makes a post-mortem photograph an example of its kind is not only the presence of a dead body in front of a camera, but also the symbolic iconographical elements that emphasize death and construct images of mourning and longing around the body of the deceased.

Although not traditional in Turkey, post-mortem photographs produced at commercial photography studios or captured in cemeteries, as a part of funerary rituals before burial, do exist. These examples mostly relate to Istanbul's non-Muslim minorities. $^{11}$ (Figures 12 and 13).

The photograph reproduced in Figure 12, taken by the well-known Sebah photography studio in Istanbul, is among the photographs this researcher surveyed: a unique post-mortem photograph of a child - unique in that it has the basic characteristics of the Victorian post-mortem photograph. Typically, the deceased, dressed neatly, is represented as if in sleep. The child's arms are crossed over his/her chest and funerary flowers are included in the foreground. It is nonetheless less theatrical than Victorian examples. In the Victorian era, the last photograph (in some cases, the only photograph) produced of a person was crucial, as it determined how the deceased was to be remembered after his/her body had disappeared; the past is remembered through images of it, just as the departed is also remembered by his/her traces. (In line with this motivation, some Victorian mourning portraits hid the lifelessness of the subject so successfully that the true purpose can only be revealed by the inclusion of particular iconography, including such symbols of death as a fading flower, a pair of scissors, a clock or medicine bottles.) Victorian methods for trying to create the illusion of life included painting pupils on closed eyelids and positioning the deceased in an erect pose. The photograph reproduced in Figure 14 seems to be a Turkish post-mortem photograph of this kind. Unlike images of violent death, in this image death is not self-evident; as with many Victorian postmortem photographs, it is not possible to tell, just by focusing on the body, whether the young girl is alive or dead. Therefore, instead of focusing only on the body of the presumed-deceased to determine whether it is a post-mortem photograph or not, 


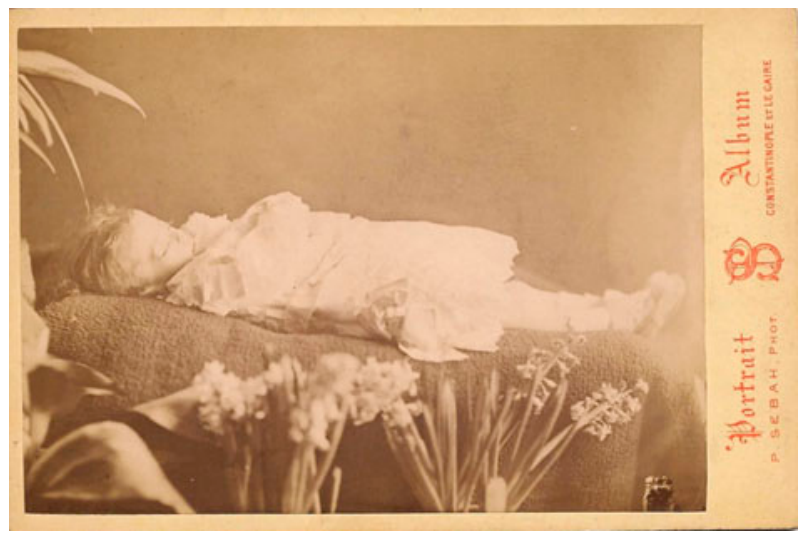

Figure 12. Post-mortem photograph of a child, taken by professional photographer Pascal Sebah, c.1880, İstanbul. Reproduced with the kind permission of Bahattin Öztuncay, B. Öztuncay collection.

it is more appropriate to focus on analysing how death is reconstructed in the photographic frame to reflect a 'narrative scene of grief' (Ruby 1995).

In the photograph reproduced in Figure 14, not only the girl's sunken and shadowed eyes but also several other textual clues imply that she is dead: the girl's awkward posture (her hands unnaturally clasped over her belly and her loosely stretching legs); the way the woman next to her (presumably the mother or a close relative) holds her (probably to support her lifeless body), with a sombre expression on her face and avoiding directly gazing at the camera; and the inclusion of what was probably a favourite possession (the doll), emblematic of Victorian post-mortem photographs. All these visual signs make the image closer to a mourning photograph than to a basic photograph of a living or dead person. When we consider that post-mortem photographs were often carefully constructed to tell a visual narrative of grief and longing, the use of post-mortem iconography and staging for the camera in Figure 14 leads one to speculate that the girl is dead and that the photo-

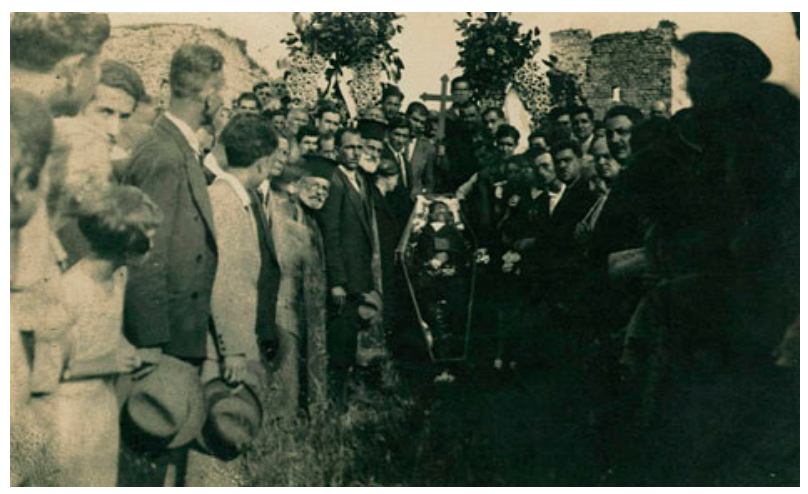

Figure 13. Mourners with open casket in a cemetery; late 1920s, Turkey. Author's private collection. 


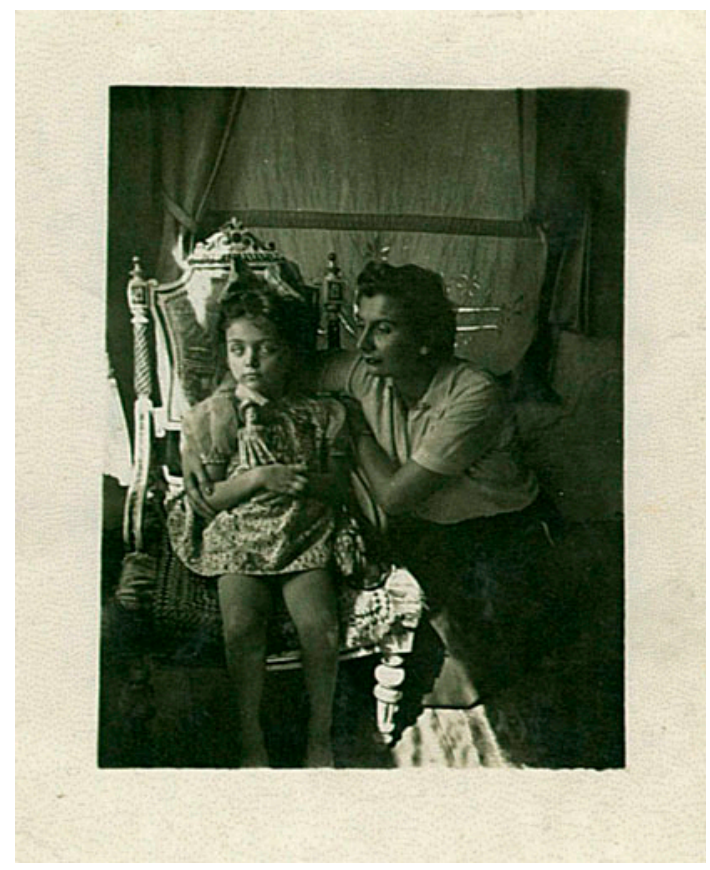

Figure 14. Post-mortem photograph of a girl in Turkey, late 1920s. Author's private collection.

graph is a rare example of post-mortem photography in Turkey; and, rarer still, one produced outside a photographic studio. Yet what makes the photograph significant is not just its being a post-mortem photograph (which one might still want to debate), nor the corpse in the photograph, but - and more importantly - its construction of the grievable.

This shift of attention from the corpse in the photograph to the visual construction of grief and the grievable points to the possibility of the existence of ways of expressing grief and longing in a photograph without including the body of the deceased. If there is no common practice of taking a last image of the dead, there may be other photographic practices that reflect and express death-related feelings, attitudes and issues. Therefore the author expanded the search parameters beyond the face of the dead to how death is visually constructed in front of the camera without necessarily including the actual body of the deceased.

\section{Visual narratives on mourning}

In critical literature, photography has frequently been associated with death. Photographs reflect the desire to be immortal or the fear of being forgotten (Bazin 1960; Berger 1980; Sontag 1979; Silverman 1996; Barthes 2000; Batchen 2004). Roland Barthes in particular sees death as implicit in every photograph. For him, this is the scandalous effect of photography: 'Ultimately, what I am seeking in the photograph taken of me', he writes, 'is death' $(2000,15)$. For Susan Sontag 'All photographs are memento mori. To take a photograph is to participate in another person's (or 
thing's) mortality, vulnerability, mutability' (1979, 15). Given that photography is a perfect tool for mourning, perhaps the close relation between death and photography could be enough to commemorate the deceased loved ones. Even though some photographs do not include the body of the deceased, such images may function as versions of post-mortem photographs and can be regarded as memorial objects commenting on the death of a friend or family member. Traditional Victorian postmortem photography was motivated not only by a will to secure a last image of the deceased, but also by the family's desire to express how they wanted to hold on to the memory of the deceased. In this sense, although some mourning photographs from the early 1900s in Turkey lack the deceased body, other visual elements representing death might have the similar function of expressing the feelings of the mourner in the face of the loss of the beloved.

The retouched and inscribed photograph shown in Figure 15a is a good example of where many iconographic elements express grief after death without picturing the dead body. This mourning photograph displaying bereavement in a cemetery is a multilayered cultural text that portrays the lasting relationship between the deceased and the bereaved, despite the break caused by death. The tombstone reads 'Ibrahim from Trabzon' in Ottoman Turkish. The photograph

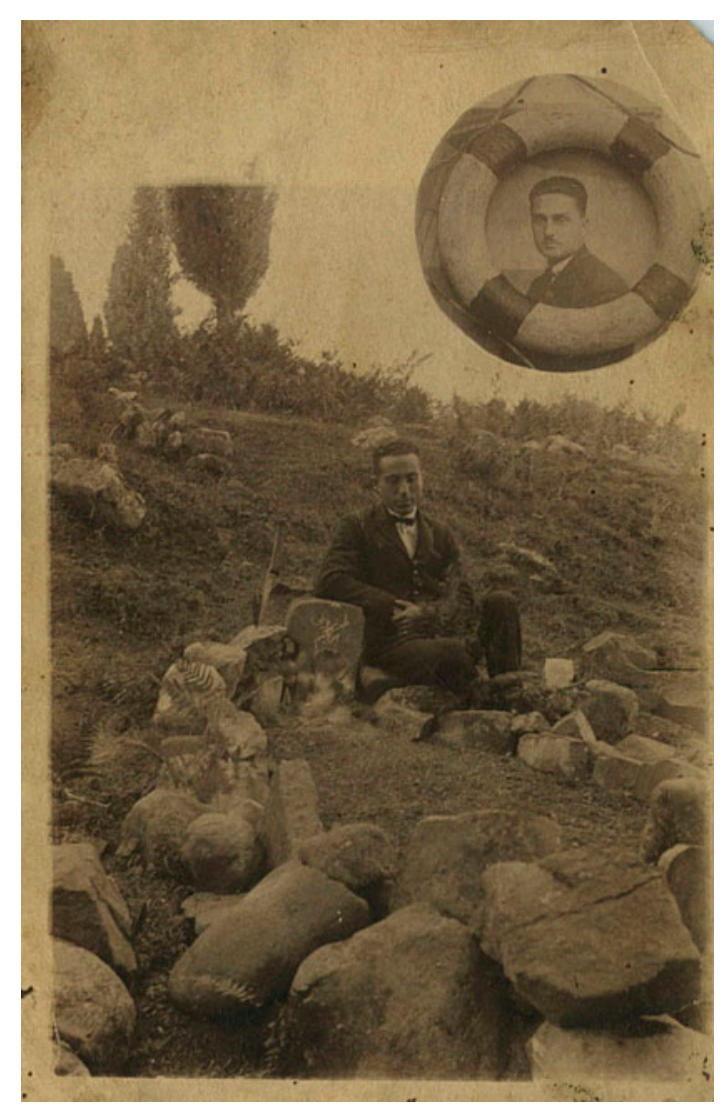

Figure 15a. The front of the modified and inscribed memorial photograph dated 6 July 1926, Turkey. Author's private collection. 
includes a pre-mortem image of the deceased, an iconographical element specific to Victorian funerary photographs. Instead of being held by the mourner, the portrait image - probably of Mr Ibrahim - was added later to the photograph by a retouch. Although this mourning photograph does not seem to include Mr Ibrahim's body, the body is not actually absent; it is merely not visible, because it is covered with earth. Although Mr Ibrahim is not physically visible, as in traditional post-mortem photography, his presence and the pain of his absence are emphasized several times in the image. He is present in the text written on the gravestone, and visible by the inclusion of his portrait at top right. While looking at the portrait of $\mathrm{Mr}$ Ibrahim in the cemetery context, one must accept his simultaneous absence and presence.

The man sitting at the graveside gazes at the grave of $\mathrm{Mr}$ Ibrahim. The direction of his gaze invites the viewer to acknowledge the grave and thus the dead body. His folded hands illustrate his respect for the deceased. He sits as if perhaps in dialogue with Mr Ibrahim. On the back of the photograph (Figure 15b), there is a hint of what he could be saying: 'In my life without Ibrahim I am miserable and preoccupied with haunting memories of love and affection, and recall his life and death' (author's translation). The photograph can be interpreted as the mourner's

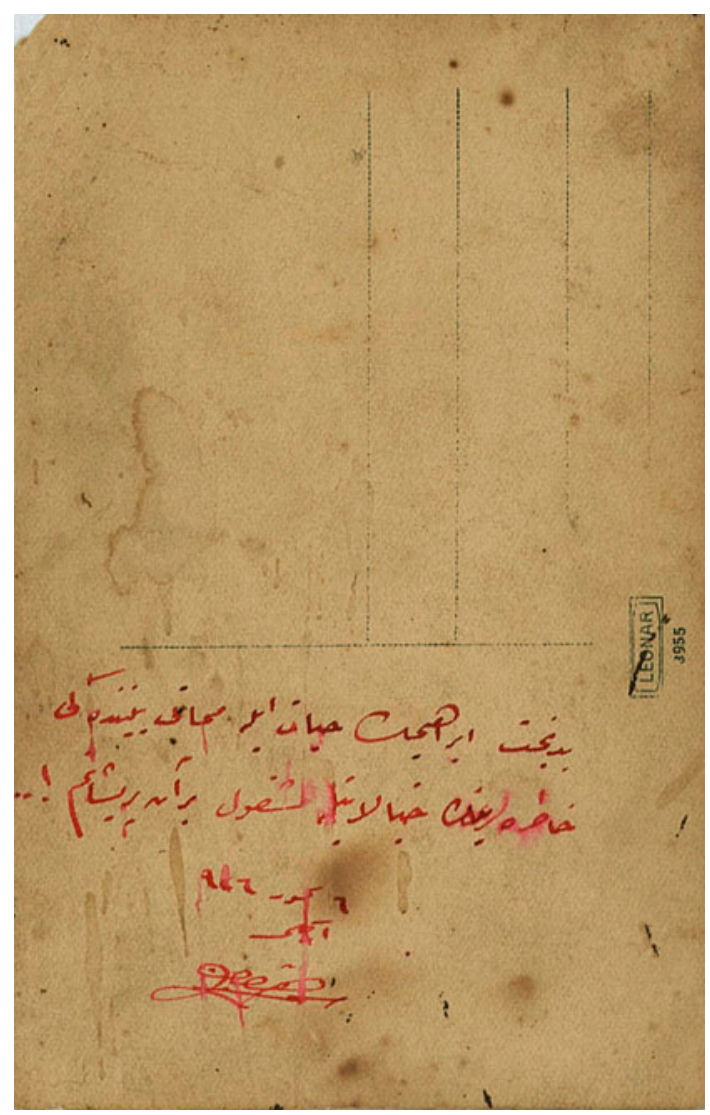

Figure 15b. The back of the modified and inscribed memorial photograph dated 6 July 1926, Turkey. Author's private collection. 
effort to remember the deceased, and a confirmation that this memory is constructed in the same way as the tradition of post-mortem photography. With the lamentation, the body language, the mourner's clothing and the added modified portrait of Mr Ibrahim, this layered mourning photograph involves the same theatricality that one can observe in Victorian post-mortem photography. Mr Ibrahim's physical body hidden in the grave, his figurative body seen in the photographic representation, and the subject at the graveside expressing his misery about the loss with a text work together to present an image of mourning. These elements function to reinterpret death in front of the camera to comment on the loss of a loved one. The image has a performative aspect that provides evidence of the man's sorrow, together with his wish to be depicted while mourning. This photograph is not only an outcome of a desire to secure the image of the deceased; it is also an attempt to express the mourner's desire not to forget Mr Ibrahim. As Geoffrey Batchen (2004) comments, it is as if the mourner wanted to be remembered while remembering. Such a photographic construction can be regarded as an alteration of the post-mortem photography tradition. Even though it does not display the deceased body, it can be considered as intended for use as a tool for grieving, because just like theatrical Victorian post-mortem photographs - which proves the sorrow of the family together with serving their aim to be depicted while mourning - in this image loss is (re)constructed.

An early example of visual mourning narratives produced in the Ottoman Empire dates back to 1878 (see Figure 16), in which a portrait of Mehmed Ali Pasha is photographed in a studio with his sons-in-law: Hasan Enver, Ismail Fazıl and Hüseyin Hüsnü (Öztuncay 2003, 69). In this photograph, the portrait sits on a stool in the centre of the photograph, which leads the viewer to consider the empty space and missing person. Carolyn Steedman argues that 'an absence is not nothing, but is rather the space left by what has gone: how the emptiness indicates how once it was filled and animated' (cited in Ahıska 2006, 22; emphasis in original). In such examples of a photograph-within-a-photograph composition, it is as if the

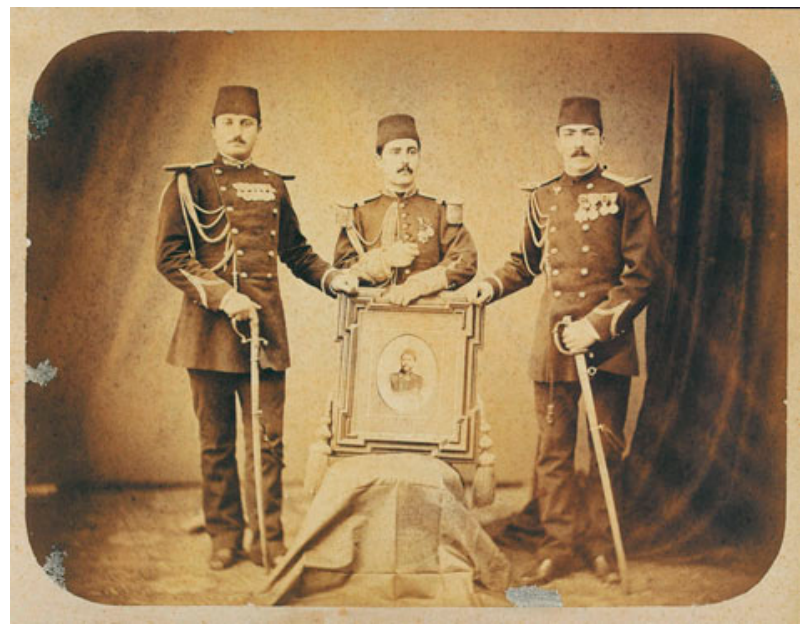

Figure 16. A photograph within a photograph from the Ottoman era, 1879 (Öztuncay 2003, 69). 
mourners need to fill the 'emptiness' caused by the loss of the loved one. Therefore, in the photograph reproduced in Figure 16, instead of Mehmet Ali Pasha sitting on the stool surrounded by his relatives, there is a photograph of him. As he cannot be present at the studio or share the same space with his family, his representation is used. In such constructions, the dead body is neither present (as in Figure 14) nor hidden (as in Figure 15); the real body of the loved one is replaced by a symbolic one: the photographic body/representation. The symbolic body of the Pasha that is sitting on an ottoman serves to preserve a mental image of him. At the same time, it signals that no one can take his place. Because photography represents memory, such a composition could be read as paying respect to the deceased, implying that his absence will be filled with his memory and that he will not be forgotten.

Such constructed images (Figures 15 and 16), although they do not directly capture the dead body of the beloved, can be regarded as being within the framework of mourning photography in that they are also created to memorialize the deceased. These examples achieve this, however, by signifying not presence but exactly the opposite: absence. In this context, one can say that the irony of the tradition of post-mortem photography is that even though the body is present (and made to look as alive as possible), the spirit/person is not; and that, more than anything else, seems to symbolize absence. In the photograph reproduced in Figure 14, where the efforts to make the deceased girl look alive are blatant, this only seems to underscore her absence more.

By focusing on a theme that has been rendered invisible or marginalized both in Muslim Turkish culture and in Turkish archives, and bringing together a variety of dispossessed death and mourning photographs from alternative sources, this article has shed some light on a new and promising study area. It is hoped that this modest effort will inspire further discussions of death and mourning photography, at both a local and a global level.

\section{Acknowledgements}

The author is indebted to her thesis supervisor, Asst. Prof. Dilek Kaya, for her unflagging support and for her insightful comments.

\section{Notes}

1. Cited in George 2005, 136.

2. Despite having photography sections, the archives that could not be visited were Yap1 Kredi Bank Sermet Çifter Archive (closed for inventory works); IRCICA: Research Center for Islamic History, Art and Culture (not open to researchers); and Istanbul University Library (closed for renovations). Relevant photographs were mostly found in the Photo Film Archive of the Office of the Prime Minister, the Directorate General of Press and Information; the Archive of the Turkish Revolution History Institute at Ankara University Faculty of Languages, History and Geography; the Archive and Library of the Turkish Red Crescent; the Ottoman Bank Archives and Research Center; and the Atatürk Library of Istanbul Metropolitan Municipality.

3. In some Victorian post-mortem photographs, the dead body is constructed to create a visual depiction of the dead as if in a peaceful sleep or as if living. For Jay Ruby, “"the last sleep" pose represents an attempt to actually conceal death' $(1995,72)$.

4. John Troyer discusses how nineteenth-century preservation technologies altered the human corpse and transformed the dead body into something new: 'a photographic 
image', 'a dead body that looked alive' $(2007,22)$. For him, through such efforts 'a specific kind of "alive but dead" human body is produced' $(2007,25)$.

5. The search engine on the website of the Turkish Department of Public Order (http:// www.asayis.pol.tr/kbcara.asp), 'the unidentified body search engine', is interesting in this sense, as it allows everyone to access its photography database of dead bodies. Here, contrary to established taboos, the 'unidentified' status seems to legitimize viewing these photographs of the dead.

6. These photographs - found in the archives of the Turkish Revolution History Institute, the Ottoman Bank Archives and Research Center, the websites of the British Museum and the Library of Congress, and some secondhand bookstores in Istanbul -

7. These courts were established in 1920 during the War of Independence in Ankara, Eskişehir, Konya, Izmir, Sivas, Kastamonu, Diyarbakır and other locales. Some were closed in 1921, but reopened to hear cases between 1923 and 1927.

8. Some of the photographs in this series show dead bodies lying alone in village streets or near ruins, representing the violent death of the familiar awkwardly lying in the public domain, outside the war arena. In this sense, these can be regarded as 'atrocity photographs', as described by Prosser, relying 'on showing people whose condition is often emblematized in their states of undress, or nakedness, or other forms of bodily vulnerability' $(2012,9)$. Some photographs are captioned, and one of them has the following explanation: 'Photographs taken following the Great Offensive showing destruction and killing by the Greeks in Bursa and Uşak'.

9. Unfortunately, not all the photographs discussed can be presented here because it was difficult to obtain relevant photographs from the archives. Written requests for copies were denied several times, with no valid explanations.

10. There are several questions to be raised here concerning who took the photographs. What was the motivation for taking these photos? Did the photographer guide the families to stand near the deceased? Do the families have a copy of the photograph as a memoriam? These questions remain unanswered because the archives gave no information about the photographs, the author was not allowed to see the original album containing these images, and the author was not given all the copies she requested.

11. I have encountered no examples of post-mortem photographs of natural deaths in the Muslim community, except for one: the image of Mustafa Kemal Atatürk, the founder of the Turkish Republic, taken in his bed on 10 November 1938, the day he died. It is held at the Photo Film Archive of the Prime Ministry. It is also important to note that sculptor Kenan Yoltuç created a death mask of Atatürk that day. Atatürk was, and remains, a politically and historically important figure whose death resulted in public nationwide mourning; this may explain why a post-mortem photograph of him was taken

\section{Notes on contributor}

Pelin Aytemiz is a research assistant in the Faculty of Communication at Başkent University. She recently received her $\mathrm{PhD}$ from the Graduate School of Economics and Social Sciences at Ihsan Doğramac1 Bilkent University. Her dissertation 'Representing Absence and the Absent One: Remembering and Longing Through Mourning Photography' aims to establish an account of mourning through photographic constructions, which can be considered as a meditation of the mourner on the oscillation of the presence/absence of the deceased.

\section{References}

Ahıska, Meltem. 2006. "Occidentalism and Registers of Truth: The Politics of Archives in Turkey." New Perspectives on Turkey. 34: 9-29.

Barthes, Roland. 2000. Camera Lucida: Reflections on Photography. Translated by Richard and Howard. London: Vintage.

Batchen, Geoffrey. 2004. Forget Me Not: Photography and Remembrance. New York: Princeton Architectural Press.

Bazin, Andre. 1960. "The Ontology of the Photographic Image.” Film Quarterly 13 (4): 4-9. 
Berger, John. 1980. About Looking. New York: Vintage.

Burns, Stanley. 1990. Sleeping Beauty: Memorial Photography in America. Altadena, CA: Twelve Trees Press.

Eldem, Edhem. 2005. Istanbul'da Ölüm: Osmanll-Islam Kültüründe Ölüm ve Ritüelleri. Istanbul: Osmanlı Bankası Arşiv ve Araştırma Merkezi Yayınları.

George, Julia. 2005. "Visual Codes of Secrecy: Photography of Death and Projective Identification." PhD Diss., University of Wollongong.

Hallam, E., J. Hockey, and G. Howard. 1999. Beyond the Body: Death and Social Identity. London: Routledge.

Larsson, Göran. 2011. Muslims and the New Media: Historical and Contemporary Debates. Farnham: Ashgate.

Linkman, Audrey. 2011. Photography and Death. London: Reaktion.

Özel, Oktay. 2012. "Arşivler meselemiz: Siyaset kurumunun tarihçiyle tehlikeli dansı ve meșruiyet kaybı." Toplumsal Tarih 217: 24-33.

Öztuncay, Bahattin. 2003. "Post-mortem Fotograflar." Toplumsal Tarih 110: 62-69.

Öztuncay, Bahattin. 2005. Hatıra-ı uhuvvet: Portre fotograflartn cazibesi: 1846-1950. İstanbul: Aygaz.

Prosser, Jay. 2012. "Introduction." In Picturing Atrocity: Photography in Crisis, edited by Geoffrey Batchen, Mick Gidley, Nancy Miller and Jay Prosser, 7-15. London: Reaktion.

Roberts, H. 2012. "War Trophy Photography: Proof or Pornography." In Picturing Atrocity: Photography in Crisis, edited by Geoffrey Batchen, Mick Gidley, Nancy Miller, and Jay Prosser, 201-209. London: Reaktion.

Ruby, Jay. 1995. Secure the Shadow: Death and Photography in America. Cambridge, MA: MIT Press.

Silverman, Kaja. 1996. The Threshold of the Visible World. London: Routledge.

Sontag, Susan. 1979. On Photography. London: Penguin.

Troyer, Jhon. 2007. "Embalmed Vision.” Mortality 12 (1): 22-47. 